\title{
Pension system of latvia: Case study approach
}

Inese Mavlutova ${ }^{\text {a }}$,

Stanislava Titovab,

Suggested Citation:

$j \quad j D \quad j$

Abstract 
1. Introduction

2. The Main Characteristics of Current Pension System 


$$
j \quad j \quad D
$$




$$
j \quad j \quad D
$$




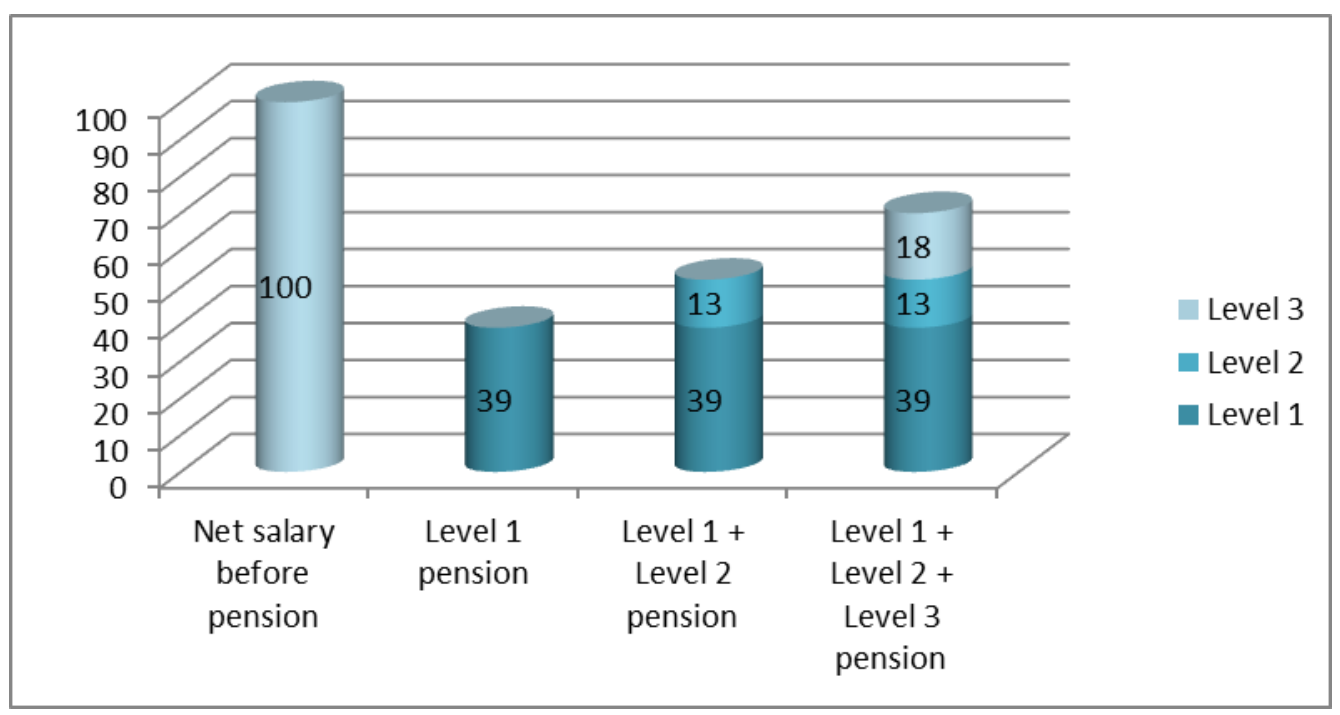

Figure 1. Compensation volume in case of participating in one of pension levels expressed in percentage. Source: compiled by the authors

the

accruals

\section{Amount of Salary}

\section{The accruals in Pension Level 2}

Period of Participation in Level 2

\section{Contributions into Level 2}

\section{Profit made from the work of Fund}

Figure 2. Factors affecting the accruals in Pension Level 2. Source: Mavlutova \& Titova, 2014 


\section{security}

security

Table 1. Total redistribution of pension capital contributions between pension system 1 and 2 in percentage. Source: SSIA, 2015

paid by the 
the

being paid

into the

the

3. Environment of Latvian Pension System.

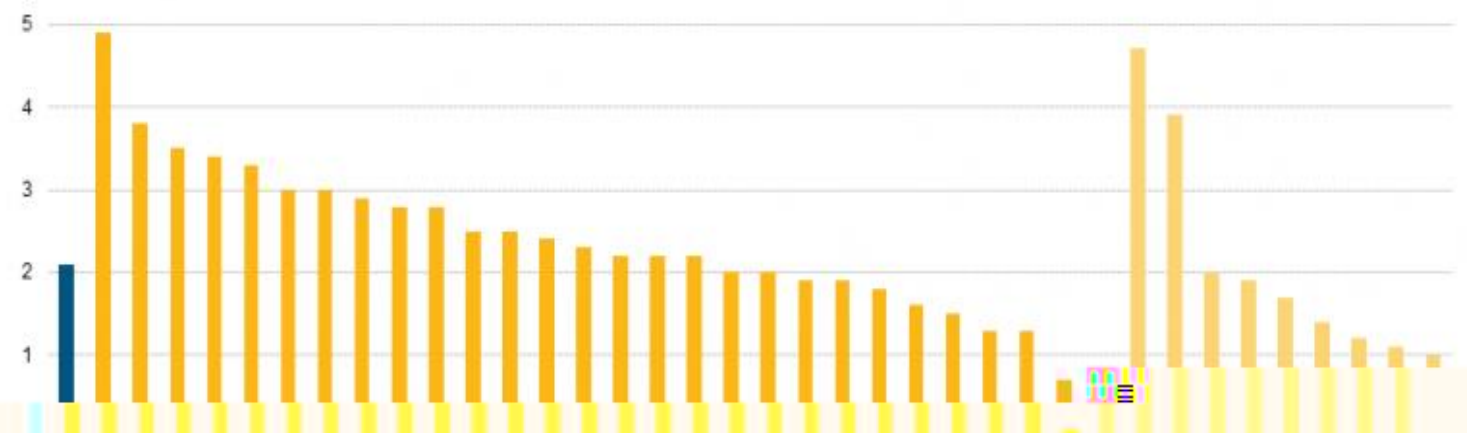

Figure 3. Increase in the share of the population aged 65 years or over between 2004 and 2014 (percentage points) Source: Eurostat, 2014 


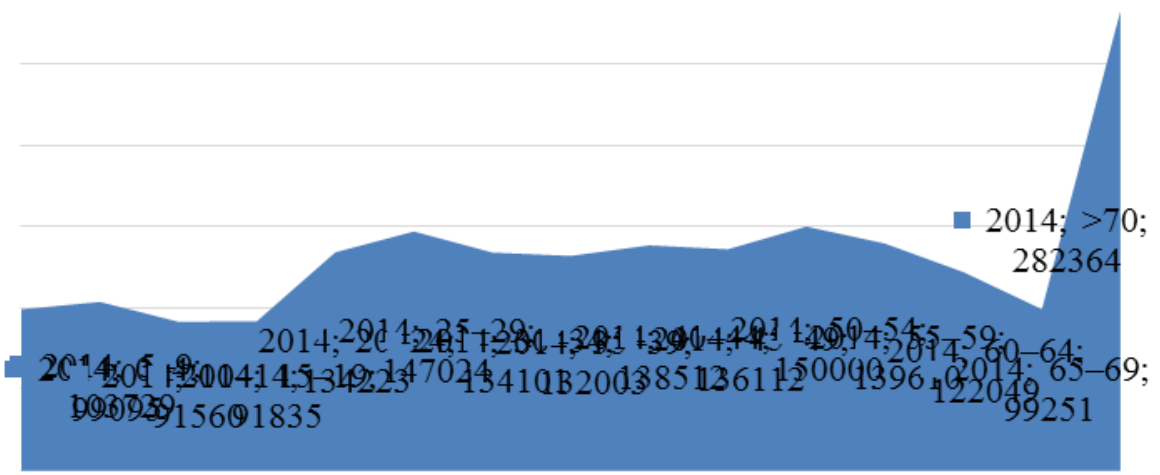

j 


\section{from what}

Table 3. Profitability of private pension plans (\%). Source: The Association of Commercial Banks of Latvia, 2015 


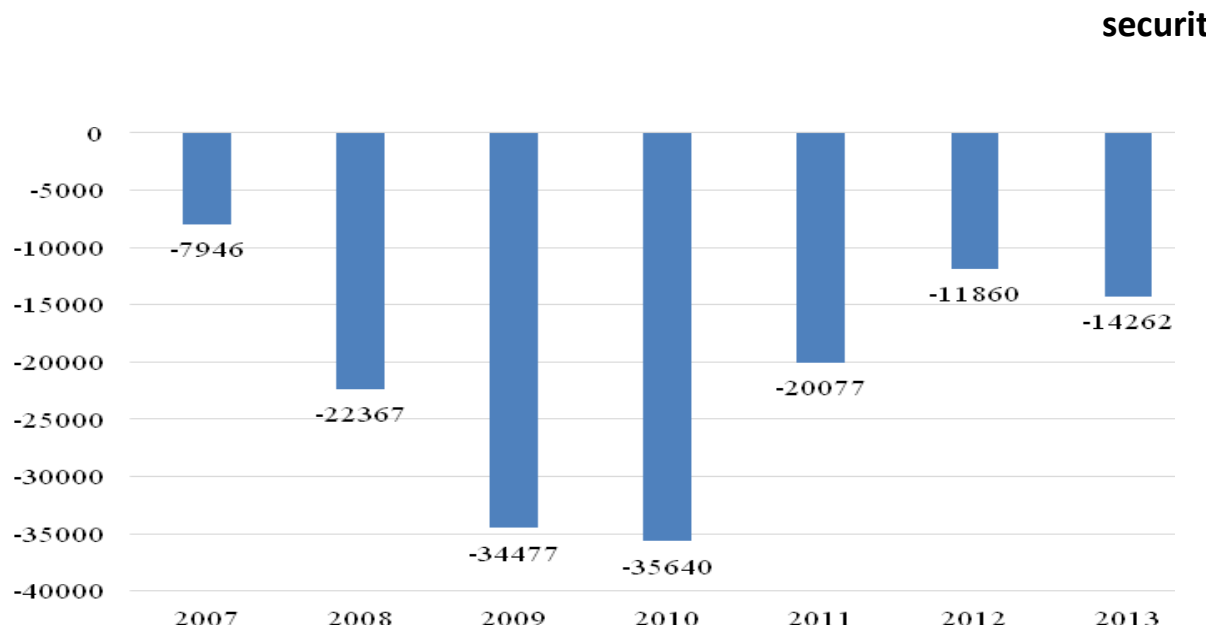

Figure 5. Imigration saldo of the inhabitants in Latvia (2007-2013). Source: CSB, 2014 in

\section{Interest Groups and Opinions}




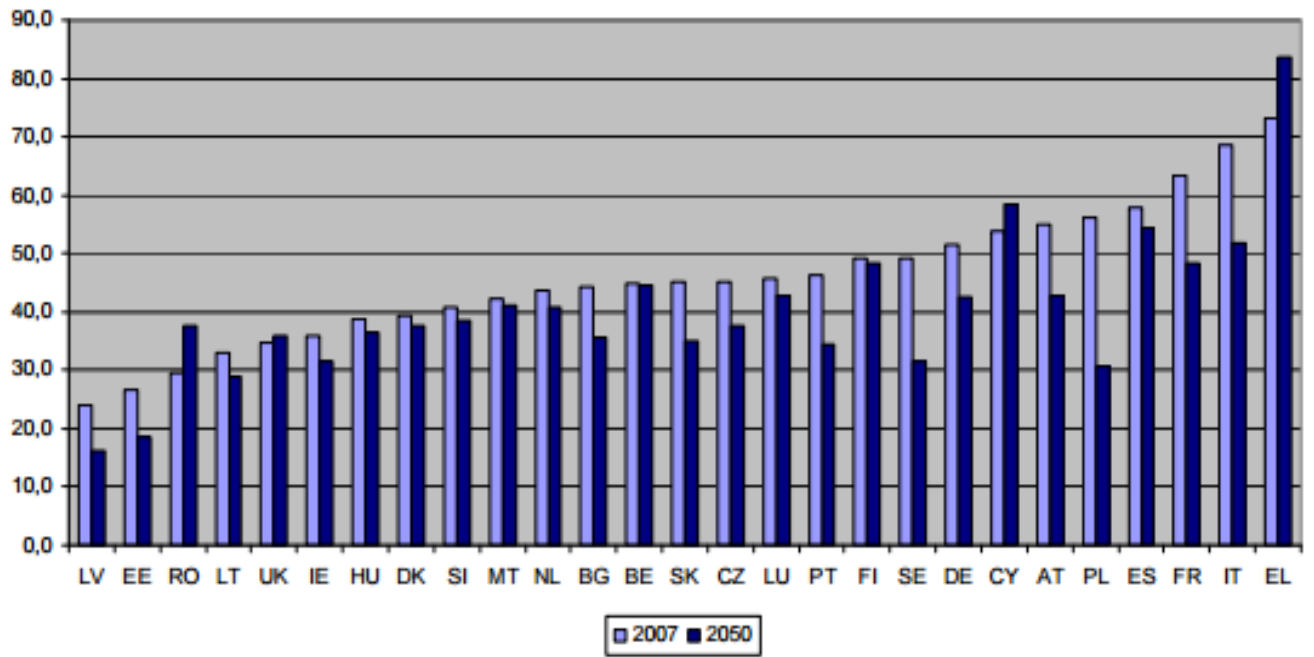

Figure 6. The benefit ratio (average gross public pension benefit divided by average gross wage) in 2007 and 2050. Source: Eichhorst et al., 2011

\section{Proposals for decision making}

\subsection{Option 1}


5.2. Option 2

5.3. Option 4

5.4. Option 5

5.5. Option 6

5.6. Option 7

5.7. Option 8

5.8. Option 9 
5.9. Option 10

5.10. Option 11

6. Key Questions for problem solving

6.1. Value - based questions

6.2. Practical - led questions 
References

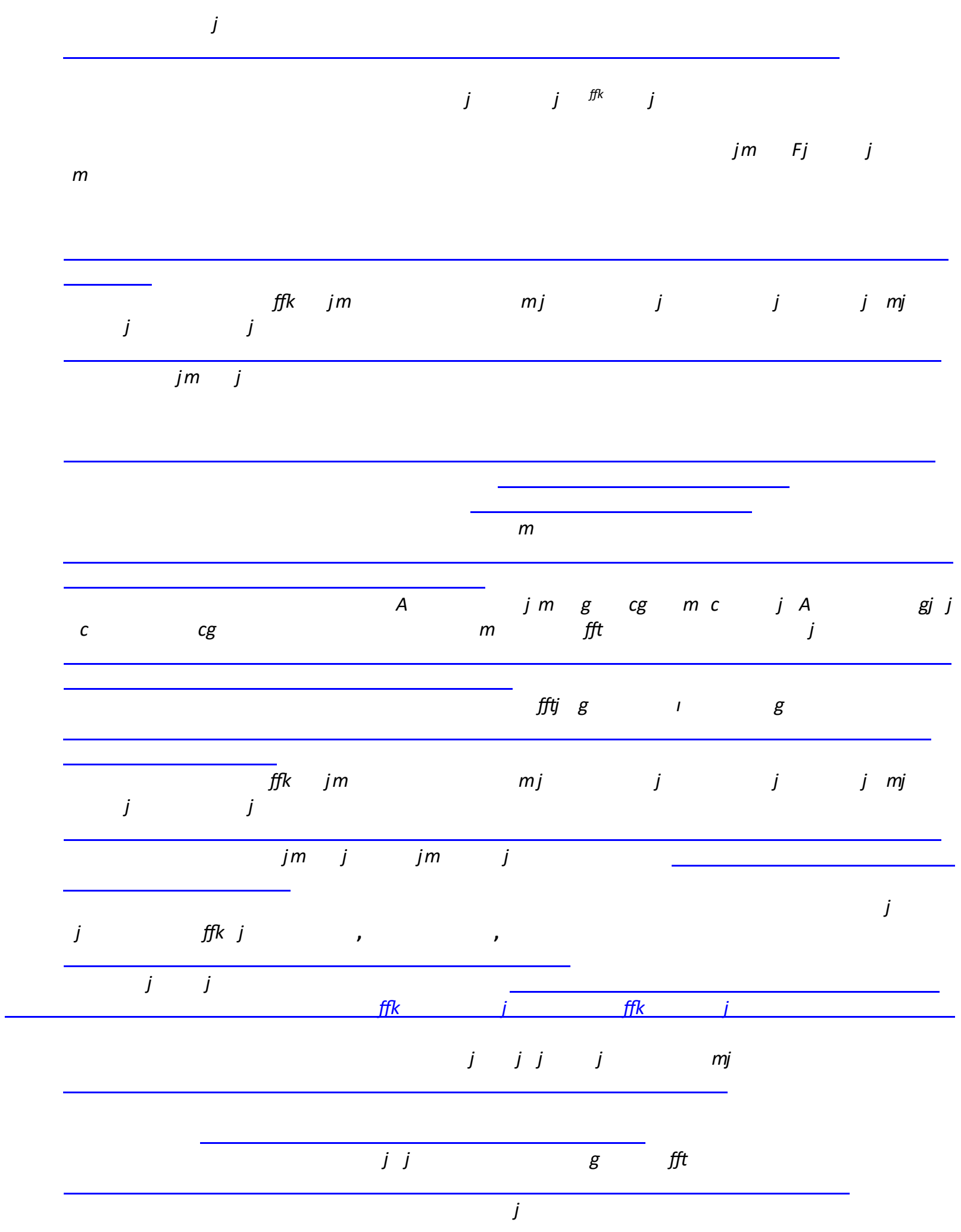




$$
\text { j } \quad j \quad D
$$

$\begin{array}{lll}m & g & f f t\end{array}$

\begin{tabular}{llllll}
\hline $\boldsymbol{C}$ & & & & & \\
& & & $j$ & $j$ \\
\hline
\end{tabular}

